of a different physician. The mother of each child infected was in a private room. Every child infected but one was a female. Five mothers out of the seven had a definite puerperal infection of greater or less degree of severity. At the time of this epidemic, for it can be called nothing else, there were delivered in the hospital forty-one children, who were cared for by the same corps of nurses and every delivery took place in the same room, and yet not one baby whose mother was in the ward became infected.

Case 6 developed in the same room that was occupied by Case 4 , and Case 7 occurred in the same room that was previously occupied by Case 3 , but between the time, that one case was discharged and another taken in some days elapsed and the room was thoroughly fumigated, cleaned and painted.

I am indebted for the facts in these reports to Dr. Hastings, Dr. E. W. Mulligan, Dr. W. T. Mulligan, Dr. Elsner and Dr. Witherspoon, and I feel that great credit is due to the management of the hospital and the nurses for the care which made it possible to control an epidemic the cause of which was so obscure.

Since this report was finished, my attention has been called to a report of four cases of this affection by Dr. Foster in the Journal of Cutaneous Diseases. His cases were not related, we believe, and in three of them there was no attempt made to ascribe an etiologic factor, and in the other it was stated that the mother had some form of eruption resembling pemphigus. In my series, Case 1 had a virulent infection of the cord which was considered etiologic to the dermatitis, while in all but one (Case 4 ) of the cases in the hospital there was a maternal condition which might have infected the child.

\section{AN AUTOMATIC CHECK FOR EXCLUDING AIR IN THE TREATMENT OF EMPYEMA.}

\section{CHAUNCEY E. TENNANT, M.D.}

DENVER.

In the evacuation of pus from the pleural cavity I have recently adopted a method of drainage which prevents in a great measure the admission of air into the pleural cavity and yet permits the free outflow of pus. The advantage of maintaining a vacuum in the chest cavity is apparent.

The suggestion of Bryant ${ }^{1}$ of attaching a collapsed rubber bulb to the end of the drainage tube after sealing the chest opening prompted an experiment with the check. The need for irrigation in a recent desperate case of empyema necessitated the adoption of the double tube to secure effective and frequent irrigation, and at the same time it afforded an excellent opportunity for the test.

The rubber tubing may be of any desired size, weight or length and with but a few minutes' work is easily converted into the ideal double current drain known as the Wetherill drainage tube, having been first devised and used by Dr. H. G. Wetherill of this city. The method of its making is probably best described in Binnie's last edition of Operative Surgery (p. 698) as follows:

Cut two holes in a long piece of drainage tubing as indicated at A and B, Figure 1. Soap and draw one end of the tube through $A$ and out at $B$, thus inverting that portion of the tube between the holes. Bend the legs of the tube down, so that the holes $A$ and $B$ will be left open for drainage. If bent in one direction they are open, if in the other closed.

1. Surg., Gyn. and Obstet., iil, p. 296.
The tube should be so bent as to bring $\mathrm{C}$ and $\mathrm{D}$ facing into the triangle. Holes $\mathrm{A}$ and $\mathrm{B}$ are cut into one side of the tube and $\mathrm{C}$ and $\mathrm{D}$ in the opposite side. A stitch at $\mathrm{E}$ holds the tube in shape (Fig. 1). The two ends of this tube are passed through two snug-fitting open-
A

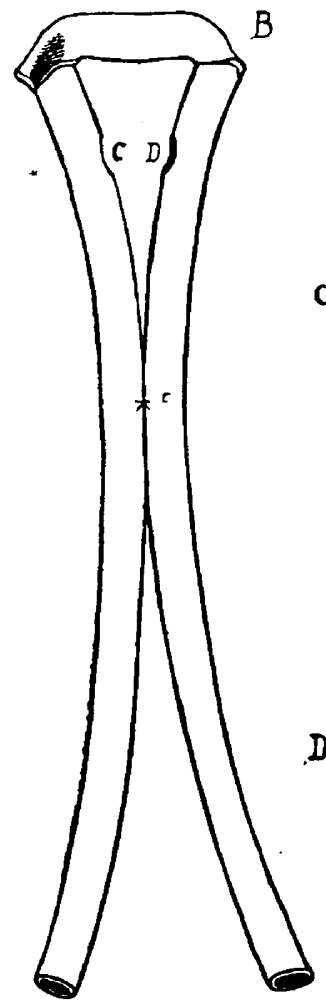

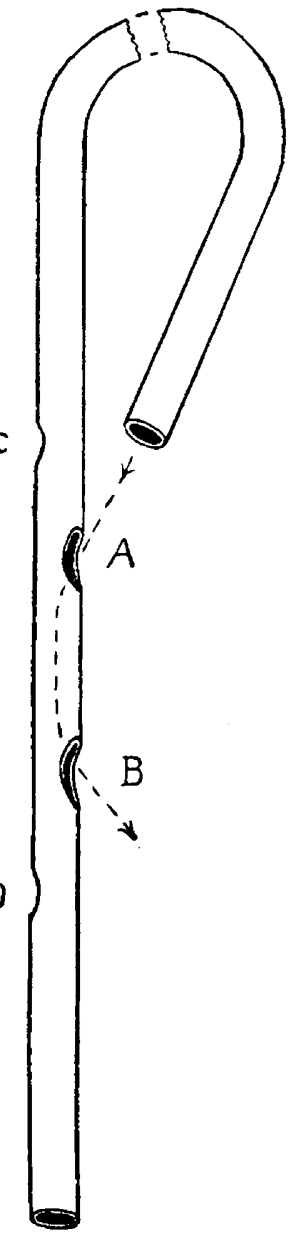

Fig. 1.-Showing method of cutting tube and inverting a portion of it.

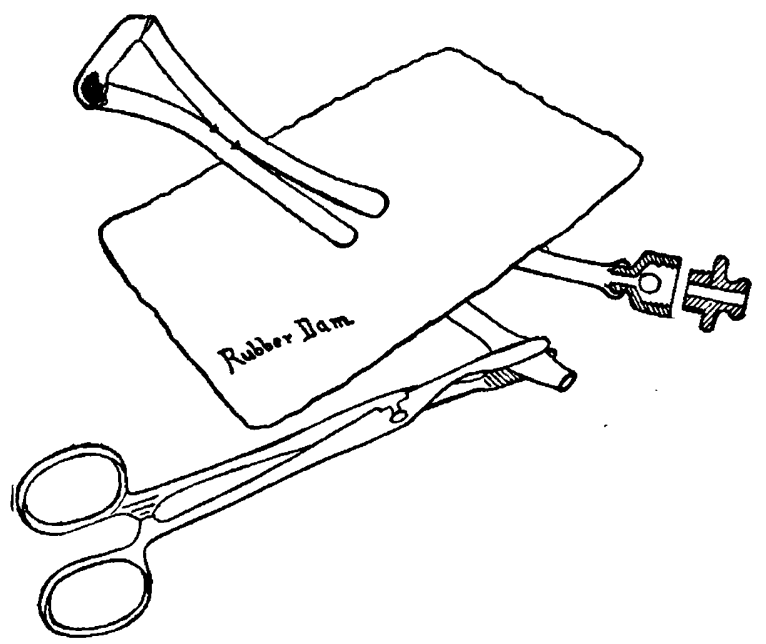

Fig. 2.-Free pnds of tube passed snugly through rubber dam; ball-valve applied at one end and hemostatic forceps at the other.

ings in a 7 by 7 inch thin dental guttapercha dam. The tube is then inserted well into the chest cavity up to the rubber dam, which latter is brought close to the chest 
wall with adhesive, thus acting as a barrier to the ingress of air around the tubes. Pus will escape underneath the dam as well as through the tube, but inspiration approximates the rubber shield to the chest wall and but little air enters the chest. To the intake end of the tube an ordinary hemostatic forcep is attached when the tube is not in use for irrigation, to the other end is placed an ordinary ball air check such as is in use in certain forms of bulb syringe. This check should be placed in either an upright or horizontal position to be effective (Fig. 2).

At my request for a check to use in this case. Dr. Roosevelt secured a large one from an abandoned syringe, and its use resulted in a free outflow of pus. little or no intake of air, and a comfortable, permanent and portable method of drainage, with irrigation tube already in place when desired.

I do not claim for this method any originality unless it may be for the application of the check, but I have found it so simple of operation, so convenient and comfortable, and withal so adaptable to almost all complications of emprema where simple rib incision is sufficient that I desire to suggest it as one method in bandling these extremely trying cases.

\section{CHRONIC ACETANILID POISONING FROM HARPER'S "BRAIN FOOD."}

\section{W. GLAZEBROOK, M.D. WASHINGTON, D. C.}

. Having read with much interest Dr. Wynn's report ${ }^{1}$ of a case of acetanilid poisoning, I desire to give an experience somewhat similar which has come to my attention during the last few weeks:

History:-Mrs. W., aged 45, presented herself at my office for treatment, with a history of general malaise, drowsiness to the extent of falling to sleep while sitting at her work, marked fatigue with little exertion, numbness in her lower extremities, with a certain degree of interference with locomotion, the symptoms having come on gradually during the last few months. She had attributed the condition to "change of life" or malaria.

Examination.-There was a marked bluish-white palor and general puffiness of the skin, more marked below the eyes; her lips were of a dark blue color and the conjunctivæ a peculiar bluish-red. The nails were a blackish-blue and the veins beneath the tongue were greatly enlarged. There was marked tremor of the extremities, with slight atrophy of the calf muscles. Respirations were about 22 , with a pulse rate of 120 . After a thorough examination I felt satisfied that there was no organic disease. Examination of the blood showed a red count of 4,600,000, witl a pressure of $130 \mathrm{~mm}$. On in quiring as to whether she suffered from insomnia, or headaches, or ever took medicines for these conditions, she replied in the negative.

Treatment. - She was put to bed and watched. Stopping one day at a drug store in her neighborhood, I asked the proprietor if Mrs. W. ever procured any drugs from him. To this inquiry, he replied in a jocular manner as follows: "If you doctors asked your druggists of tener about your patients you would be aware of many things; she has been buying a headache cure from $\mathrm{my}$ store for the last five years, during the last few months she has purchased one bottle every day." I secured a bottle of the preparation, which is put up by R. N. Harper, Washington, D. C. According to the label it contains $16 \mathrm{gr}$. of acetanilid and 30 per cent. alcohol to the ounce. The directions call for two teaspoonfuls (4 gr. acetanilid), every 2 or 3 nours in nervousmess. For headache, two teaspoonfuls, to be repeated in twenty minutes if relief does not follow, and again repeated in thirty minutes if the desired effect is not reached.

1. The Jovrial A. M. A., Sept. 21, 1907, p. 1027.
It states also on the label that "the use of this preparation is not followed by any depressing effects."

Under careful watching and treatment the patient's condition improved markedly and the natural color returned to her lips and nails. Her pulse, however, remained accelerated. Muscular weakness was still noticeable, and a certain anxious expression, to her countenance. When told that she was suffering from chronic acetanilid poisoning, she admitted only that several months ago she had headache and took one or two doses of this preparation.

2022 P Street, N. W.

\section{A LID ELEVATOR FOR CATARACT OPERATION. \\ EDWARD SWASEY, M.D. \\ Oculist and Aurist to Worcester City Hospital.} WORCESTER, MASS.

In an operation for removal of cataract it is a serious situation if the patient suddenly attempts to close the eye while the speculum is still in place under the lids.

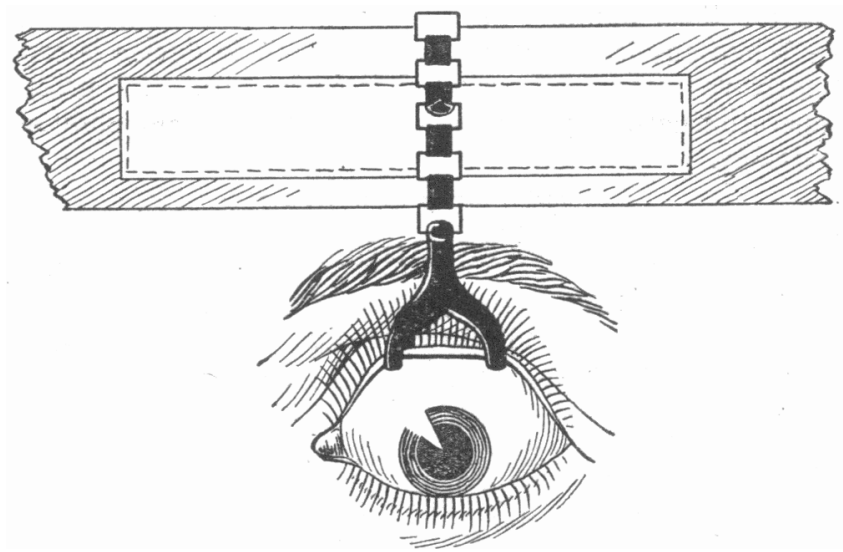

Fig. 1.-Front view of lid elevator, showing method of use.

Many an eye has been lost by this accident after the corneal section has been completed; for the lens may he fcrced out, followed by a serious loss of vitreous. Some of our most skilful and experienced operators have entirely done away with the use of the speculum for this

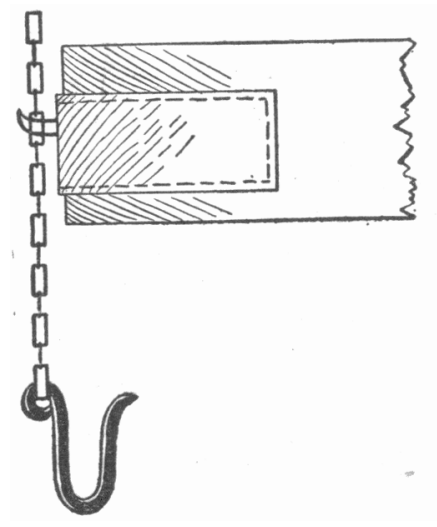

Fig. 2.-Side view of lid elevator, showing size of hook and method of attaching linked chain to head-band.

reason, and in its place use the thumb and fingers to keep the lids open, or they have a trained assistant to do this, or use a lid elevator. But not all operators can have such an assistant and at all times. Others remove the speculum as soon as the corneal section is finished and the capsule opened.

'To avoid this source of danger as far as possible, and 